\title{
Treatment of Adeno-Squamous Cell Carcinoma at the Posterior Tongue via Median Glossotomy Approach
}

\author{
So-Yoon Lee ${ }^{1}$ and Eun Chang Choi $^{2}$ \\ ${ }^{\prime}$ Department of Otorhinolaryngology-Head and Neck Surgery, CHA Bundang Medical Center, CHA University, Seongnam; and \\ ${ }^{2}$ Department of Otorhinolaryngology-Head and Neck Surgery, Yonsei University College of Medicine, Seoul, Korea
}

설 정중절개 접근을 이용한 후방 설 선-편평 상피 세포암의 치료

이 소 윤 $^{1}$ 최 은 창 ${ }^{2}$

차의과학대학교 분당차병원 이비인후과, ${ }^{1}$ 연세대학교 의과대학 이비인후과학교실 ${ }^{2}$

\author{
Received August 18, 2015 \\ Revised October 5, 2015 \\ Accepted October 21, 2015 \\ Address for correspondence \\ Eun Chang Choi, MD, PhD \\ Department of Otorhinolaryngology- \\ Head and Neck Surgery, \\ Yonsei University \\ College of Medicine, \\ 50-1 Yonsei-ro, Seodaemun-gu, \\ Seoul 03722, Korea \\ Tel $+82-2-2228-3600$ \\ Fax $+82-2-393-0580$ \\ E-mail eunchangmd@yuhs.ac
}

\begin{abstract}
We report a rare case of adeno-squamous cell carcinoma (ASC) that was successfully treated via a median glossotomy approach at the center of the posterior tongue. The AJCC stages were IVa (T1, N2c, M0). The patient underwent bilateral modified radical neck dissection and mass excision via median glossotomy approach while tracheotomized. The patient has been followed with no evidence of recurrence for 5 years. Tongue mobility was slightly decreased because of the contracture. However, articulation was acceptable. The decreased mobility of the tongue required a slightly longer oral preparatory phase of swallowing. Although median glossotomy is acceptable only in limitted cases, it allows an excellent exposure and a safe margin to approach and excise the tumor for cases like the posterior tongue in ASC, which usually has locally aggressive invasion and poor prognosis.
\end{abstract}

Korean J Otorhinolaryngol-Head Neck Surg 2016;59(7):532-6

Key Words Adeno-squamous cell carcinoma · Median glossotomy · Tongue.

\section{Introduction}

Adeno-squamous cell carcinoma (ASC) is defined as 'a malignant tumour with histological features of both adenocarcinoma and squamous cell carcinoma (SCC)' of the upper respiratory tract in the World Health Organization classification. ${ }^{1)}$ Possible risk factors are smoking, alcohol consumption, and irritation history. It has been described in a variety of body sites: uterine cervix, lung, and pancreas. ${ }^{2}$ Floor of the mouth and the tongue are the dominant sites within the oral cavity. ${ }^{3)}$ Most cases are locally aggressive, showing marked infiltration and destruction of the surrounding tissues. Regional and wide spread metastases are frequent and the mortality rate is high. ${ }^{4)}$

A variety of procedures such as intraoral resection, pullthrough technique, mandibular lingual releasing approach, mandibulotomy, or median labiomandibular glossotomy have been described to excise tumours of the posterior tongue. However, complications such as lingual dysfunction, oro-cervical fistula, cosmetic problem or airway collapse also have been described. A median glossotomy approach is another option and is less invasive and useful to remove a lesion in the posterior tongue. ${ }^{5)}$

We report a case successfully treated via a median glossotomy approach to an ASC in the posterior tongue with a review of the literatures.

\section{Case}

A 56-year-old male patient who complained of an asymptomatic mass on both sides neck for 2 months presented at our department. Physical examination revealed an enlarged 

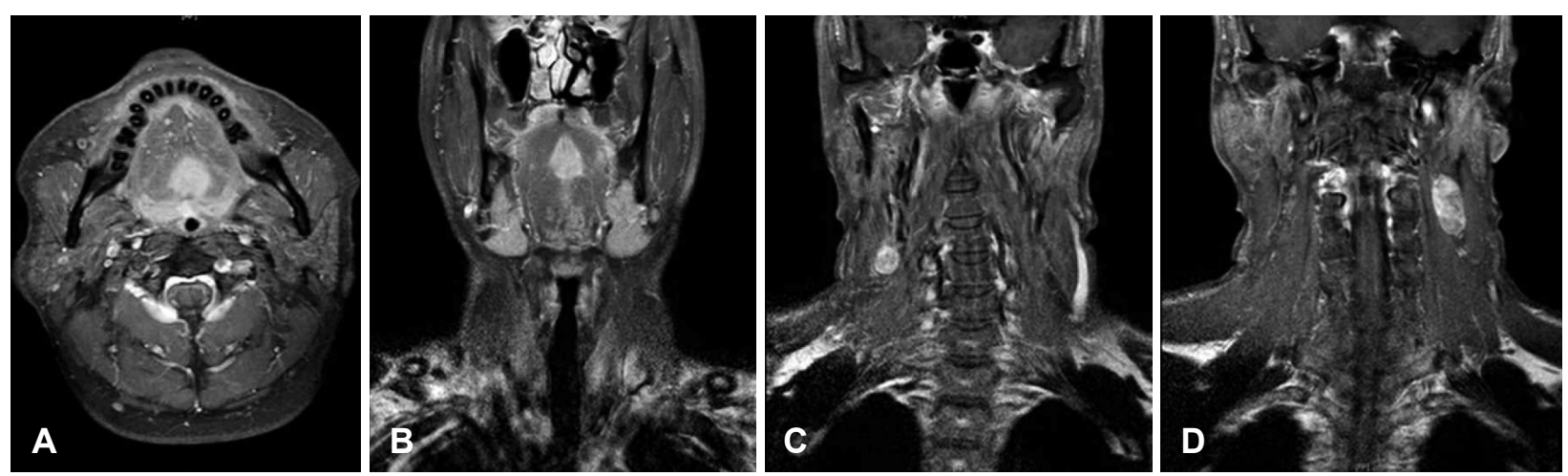

Fig. 1. Image findings. The images show a central mass of the posterior tongue with bilateral enlarged lymph nodes. Axial view: T1 gadolinium (GD) enhanced view represents an $1 \times 1.5 \mathrm{~cm}$ size and round shaped mass positioned at the center of the posterior tongue (A). Coronal view: T1 GD enhanced view represents a central tongue mass at the posterior tongue which is a well encapsulated and submucosal positioned. Invasion of the extrinsic tongue muscles is not suspected (B). Coronal view: T1 GD enhanced view shows enhanced enlarged lymph nodes. An enhanced lymph node measuring $3 \times 2 \mathrm{~cm}$ is noted on the left side neck level lla and $1 \mathrm{~cm}$ size lymph node is also noted on the right side neck level IV (C and D).
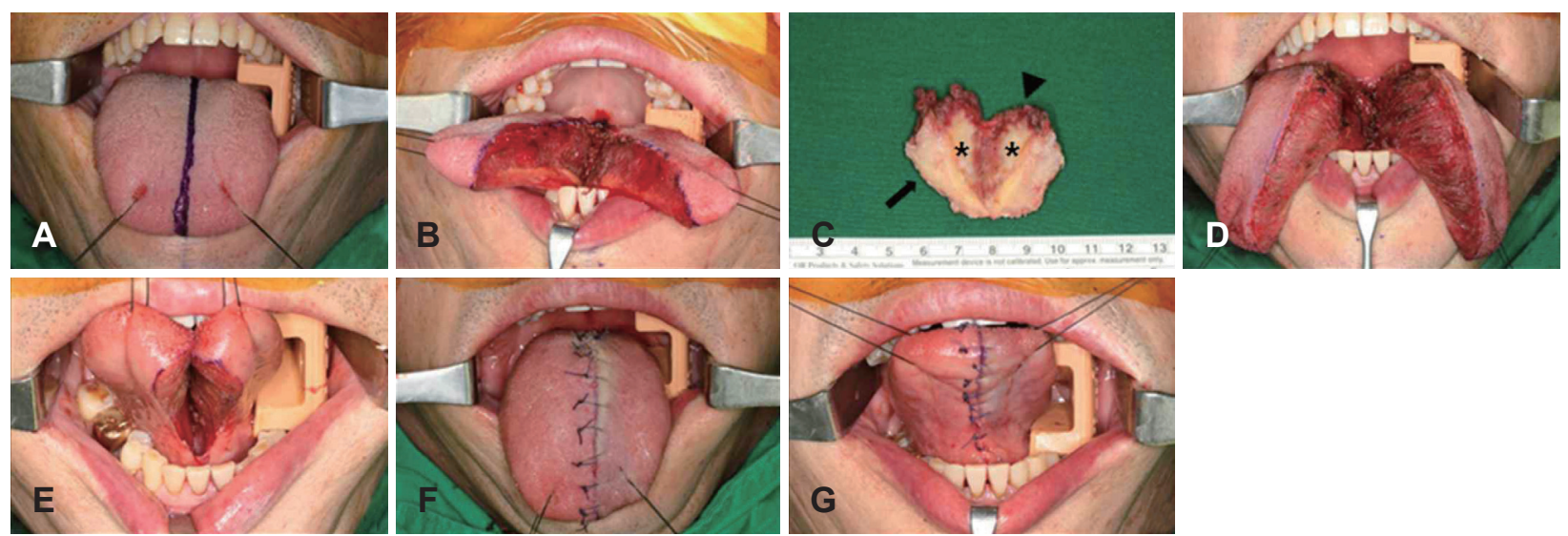

Fig. 2. Surgical procedure of mass excision via median glossotomy approach. Design of median glossotomy incision (A). Incision along median fibrous septum of the tongue (B). Excised specimen is divided half. The tumor (asterisks) is positioned submucosally (arrow, dorsal surface; arrowhead, deep surface) (C). Status post-excision of the tongue mass with safety margin (D and E). Primary repair is performed on both dorsal and ventral sides of the tongue ( $F$ and $G)$.

palpable lymph node measuring $3 \times 2 \mathrm{~cm}$ on the left and $1 \mathrm{~cm}$ size lymph node was also noted on the right side neck. In the oral cavity, a tender $1 \times 1.5 \mathrm{~cm}$ mass was palpable, and positioned at the center of the posterior tongue without mucosa ulceration. The punch biopsy result of the tongue and fine needle aspiration cytology of the regional lymph nodes were reported as SCC. On imaging studies, invasion of the extrinsic tongue muscles was not suspected (Fig. 1A and B), and palpable bilateral lymph nodes were also identified (Fig. 1C and D). On PET-CT image, there was no evidence of distant metastasis. The AJCC stage was IVa (T1, N2c, M0). The patient underwent bilateral modified radical neck dissection and mass excision via median glossotomy approach while tracheotomized. For median glossotomy approach, incision of the tongue was started along median fibrous septum using cutting cautery while traction sutures were placed at the tongue (Fig. 2A and B). The mass was excised with a $1.0 \mathrm{~cm}$ safety margin (Fig. 2C, D, and E) and primary repair was performed both dorsal and ventral side of the tongue (Fig. 2F and G). In histopathology, ASC was confirmed. The tumor demonstrated distinct areas of adenocarcinoma and SCC arising in a single tumor mass. The SCC in the superficial part of the tumor and adenocarcinoma in the deeper part of the tumor was identified (Fig. 3A). Areas of SCC were seen with sheets of epithelioid squamous cells (Fig. 3B). Areas of adenocarcinoma demonstrated distinct glandular structures (Fig. 3C and D).

The resection margins were clear and there was no evidence of perineural or lymphovascular invasion. The metastatic lymph nodes had no extracapsular invasion. Postoperative radiotherapy with $6360 \mathrm{cGy}$ was performed and the patient has been followed with no evidence of recurrence for 5 years.

On physical examination at 5 years after the initial treat- 

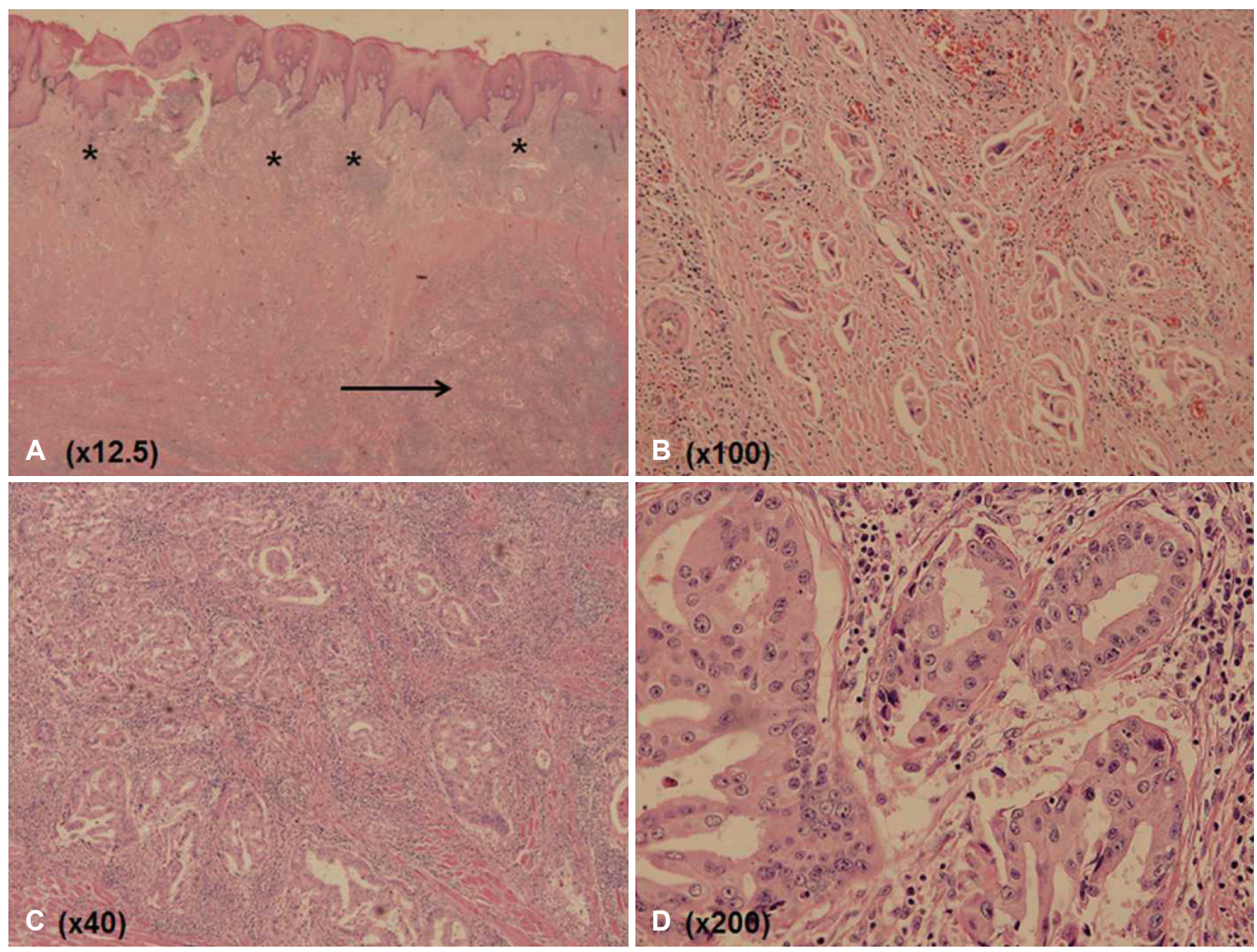

Fig. 3. Histopathology findings of adeno-squamous cell carcinoma. The tumor demonstrates distinct areas of adenocarcinoma (arrow) and SCC (asterisks) arising in a single tumor mass. The SCC in the superficial part of the tumor and adenocarcinoma in the deeper part of the tumor was identified $(\mathrm{H} \& \mathrm{E}, \times 12.5)(\mathrm{A})$. Areas of SCC are seen with sheets of epithelioid squamous cells $(\mathrm{H} \& \mathrm{E}, \times 100)(B)$. Areas of adenocarcinoma demonstrate distinct glandular structures $(H \& E, \times 40, \times 200)(C$ and D). SCC: squamous cell carcinoma.

ment, the dorsal tongue had a pothole along the incision line (Fig. 4A) and the frenulum and ventral tongue were slightly contracted (Fig. 4B). Tongue mobility was slightly decreased because of the contracture (Fig. $4 \mathrm{C}$ and D). However, articulation was acceptable although decreased mobility of the tongue required a slightly longer oral preparatory phase of swallowing.

\section{Discussion}

ASC is uncommon and originates from the mucosal epithelium of the upper respiratory tract. It is 2 to 4 times more common in men and occurs over a broad age range, 34 to 81 years. The larynx is the most common site in the head and neck accounting for $44.8 \%$ of all ASC followed by the oral cavity. The floor of the mouth and the tongue are the dominant sites in the oral cavity. ${ }^{4,6}$ But a cancer originating from the posterior tongue is uncommon. A definitive diagnosis can be made with histopathologic analysis. In histopathology, ASC is characterized by distinct and separate areas of both SCC and adenocarcinoma within the tumor mass. The SCC is found most often in the superficial part of the tumor and adenocarcinoma tends to occur in the deeper part of the tumor $^{7)}$ as our case. The diagnosis of ASC may not be apparent on small biopsies because of its biphasic character.

The clinical course is characterized by locally extremely aggressive features showing marked infiltration and destruction of the surrounding tissues. Regional and distant metastases and death from ASC are frequent. ${ }^{4)}$ A prognosis of ASC is reported to be worse than high-grade mucoepidermoid carcinoma and SCC. Head and neck SCC develops distant metastases in only $10-15 \%$ of patients and has an approximately $50 \% 5$-year overall survival rate. ${ }^{2)}$ Keelawat, et al. ${ }^{4)}$ reported the clinicopathological features of 12 ASCs of the upper aerodigestive tract which an overall survival rate was 

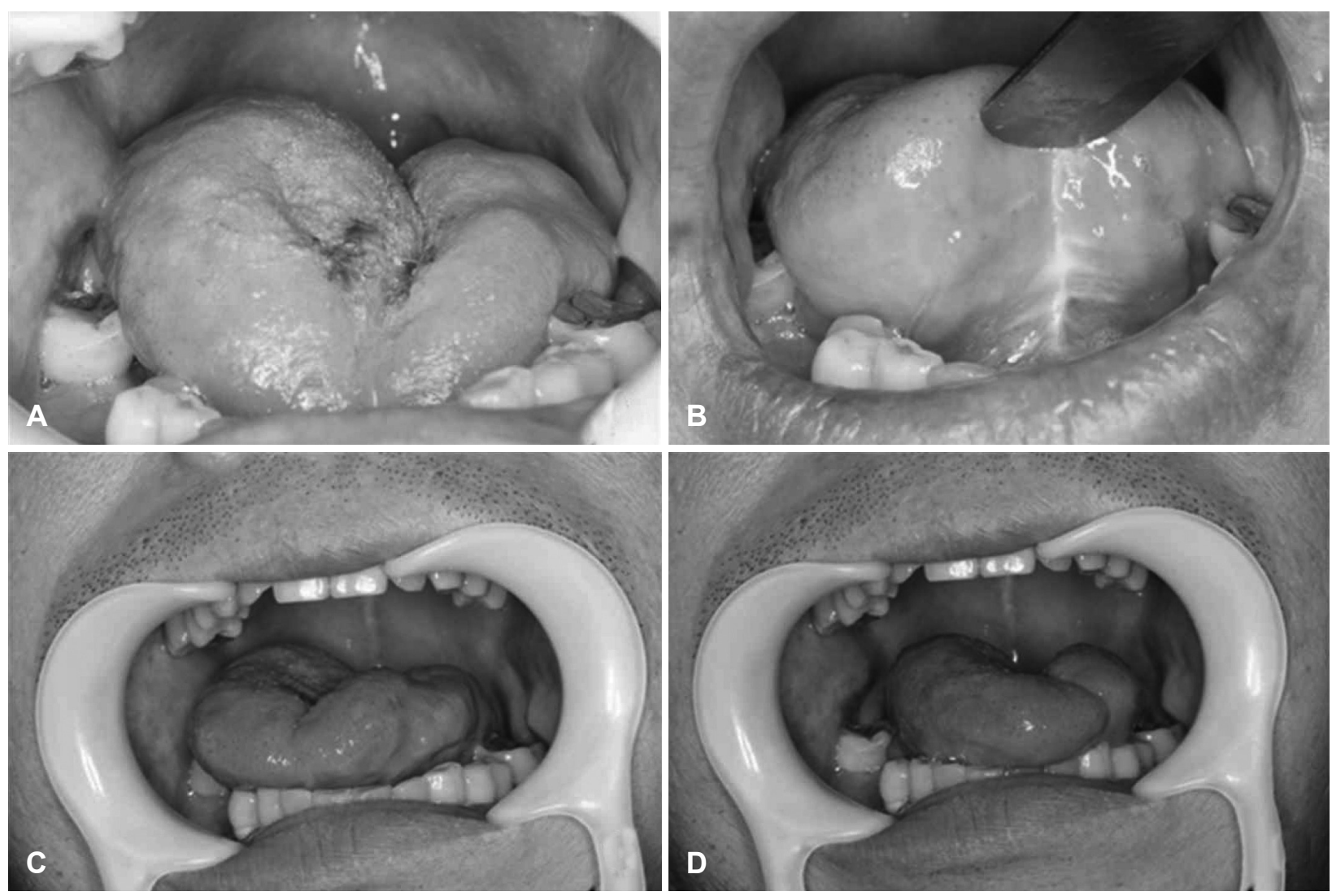

Fig. 4. Postoperative physical and functional findings (4-year after the treatment). Dorsal tongue- a pothole was identified along incision line (A). Ventral tongue-repair site and frenulum were contracted (B). Tongue movement to the right side was partially limited (C). Tongue movement to the left side was partially limited (D).

$50 \%$ at 3 years, $20 \%$ at 5 years, and $0 \%$ at 10 years, with $40 \%$ of the patients dying within 30 months.

Most authors recommend early and aggressive surgical resection for the treatment of ASC. This includes radical surgical excision of the primary lesion with combined neck dissection. Postoperative radiotherapy is often included. ${ }^{7)}$ Pain, lingual sensation, mobility, speech, taste, and wound healing must be considered when deciding the surgical approach to the tongue. To excise the posterior tongue tumor, a number of techniques have been described including a pull-through technique, mandibular lingual releasing, mandibulotomy, or medial labiomandibular glossotomy approach. These aggressive approaches result in complications of postoperative lingual dysfunction, wound dehiscence, oro-cervical fistula, cosmetic problem and airway collapse. ${ }^{8)}$ The median glossotomy approach affords excellent exposure for the resection of midline lesions of the tongue. Anatomically, incisions limited to the midline and superficial two third of the tongue are the least likely to interfere with tongue function, and are least likely to traumatize the lingual, hypoglossal or glossopharyngeal nerves. ${ }^{5)}$ In this case, a safety margin could be secured with excellent exposure with this approach. Blood loss was minimized as the tongue divided along the midline fibrous septum. The fibrous septum provides a barrier to vascular anastomoses across the midline, and incision through it makes it possible to avoid injury to the laterally located lingual vessels.

Postoperative intubation or tracheotomy is necessary for protection of the airway following median glossotomy, and intensive monitoring is mandatory until lingual swelling subsides. ${ }^{5)}$ This approach entails a risk of forked tongue if there is incomplete healing of the tip. Articulation difficulties, particularly for the consonants $/ 1 /, / \mathrm{n} /, / \mathrm{t} /$, and $/ \mathrm{d} /$ may occur. ${ }^{9)}$ In this case, the patient's articulation was acceptable. However, decreased mobility of the tongue because of the contracture slightly interrupted the oral preparatory phase of swallowing.

\section{REFERENCES}

1) Shanmugaratnam K, Sobin LH. World Health Organization histological classification of tumours. Histological typing of tumours of the upper respiratory tract and ear. 2nd ed. Berlin Heidelberg: Springer-Verlag;1991. p.38.

2) Masand RP, El-Mofty SK, Ma XJ, Luo Y, Flanagan JJ, Lewis JS Jr. 
Adenosquamous carcinoma of the head and neck: relationship to human papillomavirus and review of the literature. Head Neck Pathol 2011;5(2):108-16.

3) Yoshimura Y, Mishima K, Obara S, Yoshimura H, Maruyama R. Clinical characteristics of oral adenosquamous carcinoma: report of a case and an analysis of the reported Japanese cases. Oral Oncol 2003;39(3):309-15.

4) Keelawat S, Liu CZ, Roehm PC, Barnes L. Adenosquamous carcinoma of the upper aerodigestive tract: a clinicopathologic study of 12 cases and review of the literature. Am J Otolaryngol 2002;23(3): $160-8$.

5) Jones JE, Healy GB. Transoral surgical management of lesions of the base of the tongue. Arch Otolaryngol Head Neck Surg 1992;118
(12):1350-2.

6) Gerughty RM, Hennigar GR, Brown FM. Adenosquamous carcinoma of the nasal, oral and laryngeal cavities. A clinicopathologic survey of ten cases. Cancer 1968;22(6):1140-55.

7) Nadeau DP, Shick PC, Lindsay R. Adenosquamous carcinoma of the lateral oropharyngeal wall. Ear Nose Throat J 2010;89(11):E18-21.

8) Dean A, Alamillos F, García-López A, Sánchez J, Peñalba M. The use of Mitek pins in the mandibular lingual releasing approach to oral and/or oropharyngeal carcinomas: a technical note. J Craniomaxillofac Surg 2000;28(5):308-11.

9) Velcek FT, Klotz DH, Hill CH, Ladogana LE, Kottmeier PK. Tongue lesions in children. J Pediatr Surg 1979;14(3):238-46. 